EPJ Web of Conferences 5, 04005 (2010)

DOI:10.1051/epjconf/20100504005

(C) Owned by the authors, published by EDP Sciences, 2010

\title{
Decomposition and interpretation of Mueller matrices
}

R. Ossikovski

LPICM, Ecole Polytechnique, CNRS, 91128, Palaiseau, France

\begin{abstract}
The various decompositions of depolarizing Mueller matrices into products of basic optical devices, i.e. retarders, diattenuators and depolarizers, are critically revisited. Both "classic" as well as recently proposed factorizations are overviewed. The "depolarization aspect" is given a special attention. Experimental matrices are factorized and physically interpreted using the different decompositions. The problems of physical realizability and matrix filtering are treated in connection with the sum decomposition of a depolarizing Mueller matrix.
\end{abstract}

This is an Open Access article distributed under the terms of the Creative Commons Attribution-Noncommercial License 3.0, which permits unrestricted use, distribution, and reproduction in any noncommercial medium, provided the original work is properly cited. 